\title{
ИСПОЛЬЗОВАНИЕ ДИСТАНЦИОННЫХ ТЕХНОЛОГИЙ В ОБУЧЕНИИ УЧАЩИХСЯ С ОСОБЫМИ ОБРАЗОВАТЕЛЬНЫМИ ПОТРЕБНОСТЯМИ
}

\section{Завалина Юлия Олеговна}

ФГБОУ ВО «Вятский государственный университет»

Аннотация: Актуальность исследуемой проблемы обусловлена тем, что дистанционное технологии в обучении применяются в современном образовательном процессе. Цель статьи заключается в исследовании развития дистанционных технологий. Ведущими подходом к исследованию этой проблемы являются анализ, обобщение. Основные результаты статьи - общая картина применения дистанционного технологий применительно к обучению учащихся с особыми образоватедьными потребностями. Перечислены основные электронные образовательные платформы, информационные ресурсы и компьютерные программы, используемые в организации обучения с применением дистанционных технологий осуществляющие дистанционное обучение и центры дистанционного образования. Материалы статьи могут быть полезными для дальнейшего исследования обучения с использованием дистанционных технологий и его усовершенствования, путем решения выявленных проблем.

Ключевые слова: образовательные технологии, дистанционные технологии.

\section{Zavalina Julya Olegovna}

Abstract: The article tells about the history of distance education. The author talks about the teaching models used in the work of a speech therapist, defectologist, and teacher.

Key words: educational technology, distance technology.

Дистанционные технологии - образовательные технологии, реализуемые в основном с применением информационно-телекоммуникационных сетей при опосредованном (на расстоянии) взаимодействии обучающихся и педагогических работников [1].

В различных источниках дистанционные технологии представлены как средство обучения, как образовательная технология обучения, как разновидность 
информационно-коммуникативной технологии, как форма обучения, как образовательная система. Л.Н. Рулиене утверждает, что дистанционные технологии - это образовательные технологии, которые сами по себе представляют ценность, поскольку формируют возможности развития личности в образовании, ее способности адаптации к сложному и противоречивому миру, тем самым предоставляя гражданам ресурсы для участия в жизни общества. Главной особенностью использования дистанционных технологий в обучении Л.Н. Рулиене считает развитие у учащегося мотивации к учению, целеполагания, способности к рефлексивному осмыслению и самостоятельному поиску нового знания. Дистанционное обучение, по мнению ученого, представляет собой специально организованную среду, в которой взаимодействуют участники глобальной образовательной социальной сети [2].

Юрков Н.К. даёт следующее понятие дистанционному обучению инновационный образовательный процесс с использованием информационнокомпьютерных технологий, который помогает обучающимся реализовывать собственные образовательные цели, направленные на развитие личности и использовать полученные знания в конкретных жизненных ситуациях.

По Петрову В.С. дистанционные технологии являются современным информационно-коммуникативным средством обучения, обеспечивающим доступность образования [3].

Д. Н. Монахов рассматривает дистанционное образование как совокупность систем, функционирующем в едином образовательном пространстве. Он выделяет раз факторов, которые способствуют распространению использования дистанционных технологий в образовательном процессе в России: специфика географической протяжённости страны, включающая в себя, с одной стороны, большие территории, с другой сосредоточение научно-технических центров в крупных городах, усиление миграции населения, увеличение роли наукоемких технологи в экономике, возрастание интереса к образованию со стороны населения и др. [4].

Первое использование дистанционных технологий не было связано с современными информационно-коммуникационными технологиями, а возникло ещё до изобретения персонального компьютера; использовать дистанционные технологии начали при обучении лиц без особых образовательных потребностей в рамках освоения ими программ высшего образования. Идея обучать людей на расстоянии находит свое воплощение уже в 19 веке. Родоначальник первого дистанционного образовательного курса 
Исаак Питман в 1840 году начал обучать стенографии студентов в Великобритании, используя почтовые отправления. Высшее образование дистанционно было возможно получить уже в 1836 году - такую возможность предоставлял Лондонский Университет. Первой страной, начавшей внедрять дистанционные технологии как элемент обучения в массовой школе, стали США - в 70-е годы 19 века. В 1873 году Анна Элиот Тикнор создала и апробировала систему обучения по почте для женщин под названием «Общество Тинкор», взяв за образец английскую программу «Общество поддержки домашнего обучения». В 1874 году программу обучения с помощью почты предложил Университет штата Иллинойс [5].

В 20 веке под использованием дистанционных технологий мы чаще всего подразумеваем использование информационно-коммуникационных технологий для обучения учащихся на расстоянии. В России использование дистанционных образовательных технологий было предусмотрено Законом РФ «Об образовании» 1992 года. Последующие поправки в Закон и Приказ Минобрнауки России от 6.05 .2005 года «Об использовании дистанционных образовательных технологий» дали образовательным учреждениям возможность использовать их на всех формах обучения. Этот вид информационно-коммуникативных технологий, наиболее личностно ориентирован, предполагает составление индивидуального плана обучения / коррекционной работы, интегрированного под возможности ребенка с учётом его интересов и особых образовательных потребностей.

Кудрина Е.В отмечает следующие особенности использования дистанционных технологий: гибкость, модульность, параллельность, дистанционность, массовость, рентабельность, социальность, интернациональность [6].

Л.Н. Рулиене среди преимуществ использования дистанционных технологий в обучении отмечает оптимизацию процесса обучения, освобождение педагога от выполнения монотонной деятельности по разработке и сопровождению наглядного материала, упрощает процедуру контроля, обеспечивая ее удобство и «прозрачность».

Парахонский А.П., Венглинская Е.А., Покушалова Л.В. отмечают следующие недостатки использования дистанционных технологий в обучении учащихся с особыми образовательными потребностями: недостаток практических знаний, необходимость иметь достаточное материальнотехническое обеспечение для успешной реализации образовательного процесса 
на расстоянии, необходимость создания ряда психолого-педагогических условий.

Некоторые недостатки использования дистанционных технологий, перечисленные вышеупомянутыми авторами, относятся скорее к использованию дистанционных технологий при реализации заочной или очнозаочной форм обучения: безличностная передача знаний, недостаточно грамотно разработанный электронный образовательный ресурс, отсутствие у учащегося мотивации к осуществлению обучения самостоятельно, письменная основа обучения, отсутствие контроля со стороны преподавателя. [7, 8]. Эти недостатки отсутствуют, если дистанционные технологии применяются в рамках очной формы обучения - «Online-обучение».

Лифшиц М.В. в своей научной статье поднимает проблему успеваемости и мотивации студентов, обучающихся с использованием дистанционных технологий, описывая причины неуспеваемости, выделяя типы мотивации слушателей курсов повышения квалификации с использованием дистанционных технологий. [9]

Петров В.С. рассматривает использование дистанционных технологий в обучении как необходимость следования принципу доступности образования, в первую очередь - высшего, в современных условиях [3].

Педагоги, преподаватели, дефектологи и логопеды используют различные ресурсы в рамках использования дистанционных технологий при обучении лиц с особыми образовательными потребностями. Мосиевская И.В. предлагает для организации обучения с использованием дистанционных технологий применять собственные электронные образовательные ресурсы, создавая их с помощью pecypca voicethread.com.

Шевелева Е.И. предлагает применять интерактивные онлайн-сервисы, такие как Glogster, qrcoder.ru, http://www.LearningApps.org). Рекомендует применять QR-коды для безграничной разработки простых и доступных методов, применимых в рамках обучения с использованием дистанционных технологий.

Миропольская И.А. описывает преимущества виртуальной доску Padlet, cервиса genial.ly для работы на уроках с использованием дистанционных технологий. В качестве удобной формы контроля предлагает использование GoogleForms. Педагог описывает преимущества данных информационнокоммуникационных средств обучения для лиц с особыми образовательными 
потребностями, например, нарушениями опорно-двигательного аппарата, слуха, зрения.

Рубис Н.Ю. утверждает преимущества применения сетевых сообществ и мессенджеров для успешной реализации образовательного процесса с использованием дистанционных технологий.

Скопцева Я.Д. научно обосновывает эффективность применения дополненной реальности в обучении школьников с использованием дистанционных технологий, рассматривая приложения «HP Reveal», «Plickers», «Walla Me», «Basketball AR». [9]

Таким образом, учеными выдвинуто несколько подходов к изучению дистанционных технологий обучения, согласно которым дистанционные технологии можно рассматривать средство обучения, как образовательную технологию обучения, как разновидность информационно-коммуникативной технологии, как форму обучения, как образовательную систему. В ходе развития истории использования дистанционных технологий в обучении было сформировано множество средств обучения: начиная с почтовых отправлений, используемых в 19 веке в рамках получения высшего образования, и заканчивая разнообразием современных средств обучения, используемых в рамках обучения с использованием дистанционных технологий в наши дни на всех уровнях образования, в том числе для лиц с особыми образовательными потребностями.

\section{Список литературы}

1. Федеральный закон от 29.12.2012 N 273-Ф3 (ред. от 08.12.2020) "Об образовании в Российской Федерации" (с изм. и доп., вступ. в силу с 01.01.2021). Статья 16. Реализация образовательных программ с применением электронного обучения и дистанционных образовательных технологий.

2. Рулиене Л.Н. Дистанционное обучение как новая образовательная практика // Вестник бурятского государственного университета №1, 2011. с. 67-70.

3. Петров В.С. Дистанционное обучение как средство обеспечения доступности высшего образования // Вестник Челябинского университета. Сер. 8, Экономика. Социология. Социальная работа. - 2006. - No 5. - С. 85-88.

4. Дистанционные образовательные технологии в условиях инновационного развития России / Д. Н. Монахов [и др.]. - М. : МАКС Пресс, 2013. - 130 с. : ил. - Библиогр.: с. 120-129. - ISBN 978-5-317-04402-2 
5. Педагогический опыт: теория, методика, практика. Иуков Евгений Александрович. Дистанционное обучение детей-инвалидов и лиц с ОВЗ: Зарубежный опыт. 22.04.2015.

6. Кудрина Е.В. Современное общество и дистанционное обучение // Психолого-педагогический журнал Гаудеамус Т.2 №16, 2010. с. 57-58.

7. Парахонский А.П., Венглинская Е.А. Позитивные и негативные проявления дистанционного обучения // Международный журнал экспериментального образования №3, 2011. с.112-113

8. Покушалова Л.В. Дистанционное обучение - образовательная система будущего. // Филологические науки. Вопросы теории и практики. Тамбов: Грамота, 2009. No 2 (4). С. 200-202.

9. Дистанционное обучение: реалии и перспективы. Материалы IV Всероссийской научно-практической конференции / Сост. Матросова Н.Д. СПб: ГБУ ДПО «СПбЦОКОиИТ», 2019. - 119 с. 